 \\ doi:10.20396/revpibic2620181356
}

\section{Cordas Cósmicas e Lentes Gravitacionais}

\section{João Paulo P. Manoel, Vinicius M. e Souza}

\section{Resumo}

Estudamos o espaço-tempo da corda cósmica, começando por sua dinâmica clássica. Tentamos então alcançar um resultado análogo para o caso quântico, mas enfrentamos um problema ainda em aberto na área. Esses resultados são então usados para tentar achar análogos gravitacionais para o efeito de Aharanov-Bohm.

\section{Palavras-chave: \\ Cordas Cósmicas, Relatividade Geral, Topologia}

\section{Introdução}

Cordas cósmicas, introduzidas por Kibble, são defeitos topológicos unidimensionais hipotéticos que podem ter se formado durante a quebra de simetria espontânea no universo primordial. Atualmente, sua existência é desacreditada, mas as peculiaridades exibidas pelo espaço-tempo justificam seu estudo para modelar problemas mais complexos, como mecânica quântica na proximidade de singularidades, e defeitos topológicos mais complexos, como buracos de minhoca.

Nesse projeto, o espaço-tempo em questão foi estudado, tanto pelo ponto de vista clássico quanto pelo quântico. $\mathrm{Na}$ abordagem clássica, conseguimos determinar a dinâmica das partículas em termos de um coeficiente $\alpha$, e então relacionar esse coeficiente com a densidade linear da corda por meio do teorema de Gauss-Bonnet. Tentando achar o sistema quântico equivalente, encontramos um problema maior: as condições de contorno para a equação de Schroedinger não estão bem definidas na vizinhança da singularidade, e não vale o teorema de unicidade. Por meio do método de extensões auto-adjuntas de operadores, podemos achar as condições de contorno, e falta então determinar qual a condição de contorno adequada ao caso real (problema em aberto na área).

\section{Resultados e Discussão}

Considerando a métrica do espaço-tempo dada por $d s^{2}=-d t^{2}+d r^{2}+\alpha^{2} r^{2} d \varphi^{2}+d z^{2}$

é fácil encontrar a dinâmica de uma partícula em termos do coeficiente de déficit angular $\alpha$, e precisamos apenas relacioná-lo com a densidade linear da corda. Para isso, foi usado o formalismo de Pallatini, por meio do qual encontramos o tensor-energia momento em termos da densidade. Usando o teorema de Gauss-Bonnet, achamos a curvatura gaussiana em função do coeficiente $\alpha$, e relacionamos ambos por meio das equações de Einstein, chegando na relação $\alpha=(1-4 G \mu)$, com $\mu$ sendo a densidade linear, e usando $c=1$. Um efeito interessante de lente gravitacional surge nesse espaço-tempo: imagens extensas são duplicadas e truncadas, mas não distorcidas. Além disso, vemos que um ponto parado é geodésica, isto é, uma partícula em repouso na proximidade da corda continua em repouso, independente da densidade da corda. Dessa forma, as partículas não sentem uma "força gravitacional", e não existe análogo newtoniano.

Figura 1. Geodésicas diferenciadas pelo coeficiente de déficit angular

No caso quântico, ao considerar a equação de Schroedinger no espaço-tempo, precisamos achar as condições de contorno na corda. Usamos o método de extensões auto-adjuntas de operadores diferenciais, e exigindo que o operador hamiltoniano seja auto-adjunto achamos as condições de contorno. Porém, as condições de contorno formam uma família a 1parâmetro, e não é possível determinar qual das condições corresponde ao caso físico, isto é, temos infinitas evoluções possíveis. Esse problema surge devido à existência de uma singularidade nua, e está relacionado ao princípio da censura cósmica.

Usando esses resultados, e fazendo uma análise semelhante com a equação de Klein-Gordon nesse espaço-tempo, podemos achar resultados análogos ao efeito de Aharanov-Bohm. Um análogo possível é o da corda cósmica com momento angular, onde um campo vetorial definido em uma região singular interfere no comportamento fora dessa região. Podemos também considerar uma corda cósmica estática, e o referencial centrado na corda tem momento angular, que cria estados de energia ligados semelhantes ao de Aharanov-Bohm.

\section{Conclusão}

Apesar de muito simples, o espaço-tempo em questão permite uma análise de diversos efeitos de gravitação clássica e semi-clássica. Como mostrado, o seu estudo tem interesse não só pedagógico, como introdução à relatividade geral, mas também como modelo para problemas de quântica e gravitação.

\section{Agradecimentos}

\section{Agradecemos o apoio financeiro do CNPq.}

\footnotetext{
${ }^{1}$ S. Deser, R. Jackiw, Classical and Quantum Scattering on a Cone, Communications in Mathematical Physics 118, 495-509, 1988
}

${ }^{2}$ B. Kay, U. Studer, Boundary Conditions for Quantum Mechanics on Cones and Fields Around Cosmic Strings, Communications in Mathematical Physics 139,103-139, 1991

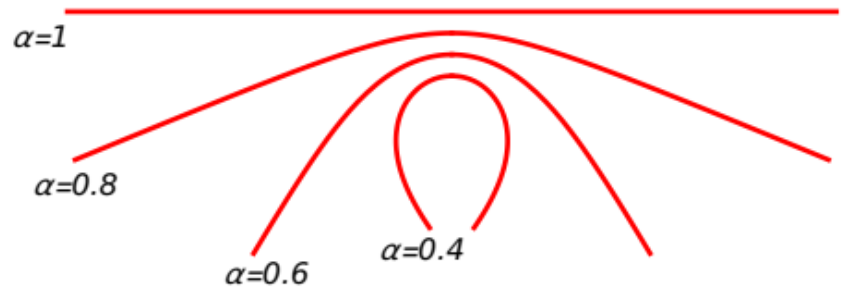

